\title{
An analysis of the phosphoproteome of immune cell lines exposed to the immunomodulatory mycotoxin deoxynivalenol
}

\author{
André Nogueira da Costa ${ }^{\mathrm{a}, *}$, Jeffrey N. Keen ${ }^{\mathrm{b}, 1}$, Christopher P. Wild ${ }^{\mathrm{a}, 2}$, John B.C. Findlay ${ }^{\mathrm{b}, \mathrm{c}}$ \\ ${ }^{a}$ Molecular Epidemiology Unit, Division of Epidemiology, Leeds Institute of Genetics, Health and Therapeutics, University of Leeds, Leeds LS2 9JT, UK \\ ${ }^{\mathrm{b}}$ Institute of Membrane and Systems Biology, Faculty of Biological Sciences, Leeds Institute of Genetics, Health and Therapeutics, University of Leeds, Leeds LS2 9JT, UK \\ ' Marie Curie Laboratory for Membrane Proteins, Department of Biology, NUI Maynooth, Co. Kildare, Ireland
}

\section{A R T I C L E I N F O}

\section{Article history:}

Received 11 November 2010

Received in revised form 17 March 2011

Accepted 1 April 2011

Available online 13 April 2011

\section{Keywords:}

Biomarker

Deoxynivalenol

Mycotoxin

Phosphoproteomics

\begin{abstract}
A B S T R A C T
The mycotoxin deoxynivalenol (DON) commonly contaminates cereal grains. It is ubiquitous in the Western European diet, although chronic, low-dose effects in humans are not well described, but immunotoxicity has been reported. In this study, two-dimensional gel electrophoresis was used to identify phosphoproteomic changes in human B (RPMI1788) and T (Jurkat E6.1) lymphocyte cell lines after exposure to modest concentrations of DON (up to $500 \mathrm{ng} / \mathrm{mL}$ ) for $24 \mathrm{~h}$. Proteins identified as having altered phosphorylation state post-treatment (C-1-tetrahydrofolate synthase, eukaryotic elongation factor 2, nucleoside diphosphate kinase A, heat shock cognate $71 \mathrm{kDa}$ protein, eukaryotic translation initiation factor 3 subunit I and growth factor receptor-bound protein 2) are involved in regulation of metabolic pathways, protein biosynthesis and signaling transduction. All exhibited a greater than 1.4-fold change, reproducible in three separate experiments consisting of 36 gels in total. Flow cytometry validated the observations for eukaryotic elongation factor 2 and growth factor receptor-bound protein 2 . These findings provide further insights as to how low dose exposure to DON may affect human immune function and may have potential as mechanismbased phosphoprotein biomarkers for DON exposure.
\end{abstract}

(C) 2011 Elsevier B.V. All rights reserved.

\section{Introduction}

Fusaria mycotoxins such as deoxynivalenol (DON), contaminate a wide range of cereal crops [1]. Epidemiological studies have implicated mycotoxins in some mass food poisoning outbreaks and DON has been one of the compounds found in highest concentrations $[2,3]$.

Abbreviations: C1-THF synthase, C-1-tetrahydrofolate synthase; DON, deoxynivalenol; eEF2, eukaryotic elongation factor 2; eIF3i, eukaryotic translation initiation factor 3 subunit I; ERK, extracellular signal-regulated kinase; GMPS, GMP synthase; GRB2, growth factor receptor-bound protein 2; Hsc70, heat shock cognate $71 \mathrm{kDa}$ protein IMDH2, Inosine-5'-monophosphate dehydrogenase 2; MFI, mean fluorescence intensity; MTT, 3-(4, 5-dimethylthiazolyl-2)-2,5-diphenyltetrazolium bromide; NDKA, nucleoside diphosphate kinase A; PE, phycoerythrin; PKR, protein kinase R; PMTDI, provisional maximum tolerable daily intake

* Corresponding author at: Molecular Carcinogenesis Group, Section of Mechanisms of Carcinogenesis, International Agency for Research on Cancer, 150 cours AlbertThomas 69372 Lyon Cedex 08, France. Tel.: + 33 472738383; fax: + 33472738322.

E-mail addresses: dacostaa@fellows.iarc.fr (A. Nogueira da Costa), jeffrey.keen@pfizer.com (J.N. Keen), director@iarc.fr (C.P. Wild), J.B.C.Findlay@leeds.ac.uk (J.B.C. Findlay).

1 Present Address: Biotherapeutics Research Department, Pfizer Ltd, LSI Building, Foresterhill, Aberdeen, AB25 2ZS, UK.

2 Present Address: International Agency for Research on Cancer, 150 Cours Albert Thomas, 69372 Lyon CEDEX 08, France.
Animal studies have shown that DON may induce generalized GI tract toxicity, emetic effects and feed refusal [4-6]. Studies in animal models and immortalized cell lines have also shown that DON exposure modulates immune function by specifically influencing proinflammatory responses and white blood cell distribution and proliferation in several organs [7-10].

The primary mode of action of DON is thought to be its ability to bind to eukaryotic ribosomes and thereby inhibit protein synthesis $[8,11]$. Secondary mechanisms such as disruption of cell signaling, differentiation, growth and macromolecular synthesis have also been associated with DON exposure [8,11].

Although biomarkers promise to provide more objective measures of DON exposure, to date few studies have been conducted to identify biomarkers of exposure or effect. Recent reports highlight the value of urinary DON as a biomarker of recent exposure [12-14] while immunoglobulins and pro-inflammatory cytokines have been proposed as potential biomarkers of effect in relation to the immunomodulatory effects of the compound $[8,15]$.

The development and application of "omics" techniques to develop potential mechanism-based biomarkers is a promising approach and we recently identified a number of proteins altered in expression following DON exposure in human cells lines [16]. We now extend this work to compare phosphoprotein expression in human B (RPMI1788) and T (Jurkat E6.1) lymphocyte cell lines exposed to DON at a maximum concentration of $500 \mathrm{ng} \mathrm{DON} / \mathrm{mL}$ for a period of 
up to $54 \mathrm{~h}$. These cell types represent major cellular components of the adaptive immune response and have been used extensively previously $[17,18]$. A panel of phosphoproteins which exhibited validated altered phosphorylation state across these cell lines is described. This is the first study looking at post-translational modifications due to DON exposure using a proteomics approach. The phosphoproteins identified may represent valuable biomarkers to further understand how chronic exposure to DON affects human immune function.

\section{Materials and methods}

\subsection{Reagents}

RPMI 1640 (+ L-glutamine) medium was from Gibco (Invitrogen Ltd., Paisley, UK); DON, 3-(4, 5-dimethylthiazolyl-2)-2,5-diphenyltetrazolium bromide (MTT), gelatine from cold water fish skin, protease inhibitor cocktail and phosphatase inhibitor cocktail were supplied by Sigma-Aldrich (Dorset, UK); ProteoExtract Protein Precipitation Kit was from Calbiochem (Merck Chemicals Ltd., Nottingham, UK); ampholytes and $24 \mathrm{~cm}$ pH 3-10 non-linear IPG strips were from Bio-Rad (Hertfordshire, UK); SYPRO Ruby and Pro-Q Diamond phosphoprotein stain was from Invitrogen (Paisley, UK); acetonitrile, formic acid and trifluoroacetic acid used for MS analysis or sample preparation were of HPLC quality (Fisher Scientific, Leicestershire, UK); HPLC-grade water was prepared with a Neptune Ultimate System (Purite Ltd., Oxon, UK); sequencing grade trypsin for protein digestion was from Promega (Southampton, UK); goat anti-rabbit IgG-PE was from Santa Cruz Biotechnology (Heidelberg, Germany); eukaryotic elongation factor 2 (eEF2) (phospho T56 + T58) rabbit monoclonal antibody was from Abcam (ref. Ab82981,UK); growth factor receptor-bound protein 2 (GRB2) rabbit polyclonal antibody against amino acid residues surrounding Y209 was from Abnova (ref. PAB4939, UK).

\subsection{Cell culture and DON treatment}

The culture and treatment with DON of the human B lymphocyte cell line (RPMI1788, ECACC, UK) and human T lymphocyte cell line (Jurkat E6.1, ECACC, UK) was performed with cells being grown at $37{ }^{\circ} \mathrm{C}$ in a humidified atmosphere consisting of $5 \% \mathrm{CO}_{2}$ air, in RPMI 1640 ( + L-glutamine) medium supplemented with $20 \%(\mathrm{v} / \mathrm{v})$ heatinactivated FCS or $10 \%(\mathrm{v} / \mathrm{v})$ heat-inactivated FCS, respectively. Cells were kept in the exponential growth phase, at a concentration of $3 \times 10^{5}$ cells $/ \mathrm{mL}$. Stock solutions and subsequent working solutions of DON were prepared in absolute ethanol. Working solutions of DON were prepared with a maximum concentration of $0.05 \%$ absolute ethanol. Vehicle control cells were prepared in the same manner as DON treated samples including the addition of the vehicle control ( $0.05 \%$ ethanol), instead of DON. Cell treatments were conducted in flat bottom 96-well and 12-well plates (Fisher Scientific, Leicestershire, UK). Cells were treated with DON for a period of up to $54 \mathrm{~h}$, with concentrations of $250 \mathrm{ng}$ and $500 \mathrm{ng}$ DON/mL for Jurkat E6.1 and RPMI1788 cells, respectively. At the end of the incubation period, cells were either stored at $-80^{\circ} \mathrm{C}$ or immediately used for cell viability measurements, proteomic studies and flow cytometry experiments. Cell viability was assessed using the 3(4, 5-dimethylthiazolyl-2)-2,5-diphenyltetrazolium bromide (MTT) assay. Cells were grown in flat bottom 96-well plates at a concentration of $6 \times 10^{5}$ cells/mL per well with DON for a period of up to $54 \mathrm{~h}$, in a humidified atmosphere consisting of $5 \% \mathrm{CO}_{2}$ air, at $37^{\circ} \mathrm{C}$. At the end of the each treatment period, $10 \mu \mathrm{L}$ of MTT were added to the cells and plates were incubated for $4 \mathrm{~h}$. Subsequently, $100 \mu \mathrm{L}$ of $10 \%$ (w/v) SDS in $0.01 \mathrm{M} \mathrm{HCl}$ were added and the plate incubated overnight. On the following day, absorbance levels were recorded at $540 \mathrm{~nm}$ and $690 \mathrm{~nm}$ using an iEMS Reader MF (Labsystems, Cambridge, UK). Each plate contained a positive control consisting of cells incubated with $9 \%(\mathrm{v} / \mathrm{v})$
Triton X-100 prior to the addition of MTT. Doses of $250 \mathrm{ng}$ DON/mL and $500 \mathrm{ng}$ DON/mL were selected on the basis of previously conducted MTT experiments for Jurkat E6.1 and RPMI1788 cell lines respectively [16].

\subsection{Cell lysis and two-dimensional gel electrophoresis}

Cells were grown in T75 tissue culture flasks and $8 \times 10^{6}$ cells were lysed with $200 \mu \mathrm{L}$ of lysis buffer ( $7 \mathrm{M}$ urea, $2 \mathrm{M}$ thiourea, $4 \%(\mathrm{w} / \mathrm{v}$ ) CHAPS, $64 \mathrm{mM}$ DTT and $1 \%(\mathrm{v} / \mathrm{v})$ protease and phosphatase inhibitor cocktails) per condition. The lysates were centrifuged at $13,250 \times \mathrm{g}$ for $15 \mathrm{~min}$ and the supernatant treated with ProteoExtract Protein Precipitation Kit (Calbiochem, Merck Chemicals Ltd., Nottingham, UK) according to the manufacturer's protocol. After resuspending the protein pellets in lysis buffer, the lysate was centrifuged at $13,250 \times g$ for $15 \mathrm{~min}$ and the supernatant collected. The protein concentration of the supernatants was determined using the Bradford assay (Bio-Rad, Hertfordshire, UK). An aliquot ( $350 \mu \mathrm{g}$ ) of each supernatant was applied to a $24 \mathrm{~cm}$ pH 3-10 non-linear IPG strip overnight, allowing for the passive rehydration of the IEF strips. IEF was carried out using the ProteanIEF system (Bio-Rad, Hertfordshire, UK) with the following program: (1) $250 \mathrm{~V}, 8 \mathrm{~h}$; (2) $10000 \mathrm{~V}, 2.5 \mathrm{~h}$; (3) $60000 \mathrm{Vh}$, at a limit of $10000 \mathrm{~V}$; (4) $500 \mathrm{~V}$ until equilibration. The first equilibration step was carried out by washing the strips for $15 \mathrm{~min}$ in a buffer containing $2 \%$ (w/v) DTT, 6 M urea, 0.05 M Tris-HCl (pH 8.8), 2\% (w/v) SDS, and 20\% $(\mathrm{v} / \mathrm{v})$ glycerol. The second equilibration step (15 $\mathrm{min})$ used the same buffer but with $2.5 \%(\mathrm{w} / \mathrm{v})$ iodoacetamide replacing DTT. For the second dimension, strips were transferred onto SDS-PAGE gels containing 10\% $(\mathrm{w} / \mathrm{v})$ premixed acrylamide, prepared with a multicasting chamber (Bio-Rad, Hertfordshire, UK). Migration was carried out for $6 \mathrm{~h}$ at a constant voltage of $200 \mathrm{~V}$ in a Protean Plus DoDecaCell tank (Bio-Rad, Hertfordshire, UK), at $10^{\circ} \mathrm{C}$. Gels were incubated in $50 \%(\mathrm{v} / \mathrm{v})$ methanol, $7 \%(\mathrm{v} / \mathrm{v})$ acetic acid overnight, were washed three times in ultra-pure water for $5 \mathrm{~min}$ and subsequently stained with Pro-Q Diamond phosphoprotein stain for $2 \mathrm{~h}$. Gels were then destained three times in a $20 \%(\mathrm{v} / \mathrm{v})$ acetonitrile, $50 \mathrm{mM}(\mathrm{w} / \mathrm{v})$ sodium acetate $\mathrm{pH} 4.0$ solution for $30 \mathrm{~min}$ and subsequently washed twice in ultra-pure water for $5 \mathrm{~min}$. After imaging and for spot excision purposes, gels were incubated overnight in SYPRO Ruby stain. On the following day, gels were washed for $30 \mathrm{~min}$ in $10 \%(\mathrm{v} / \mathrm{v})$ methanol, $7 \%(\mathrm{v} / \mathrm{v})$ acetic acid and subsequently washed twice in ultra-pure water for $5 \mathrm{~min}$ and imaged. Three independent experiments comprising triplicate samples for each condition $(n=6)$ were performed.

\subsection{Image analysis}

Gels were scanned using an FX Pro Plus imager (Bio-Rad, Hertfordshire, UK) and the images analyzed using PDQuest software version 7.3.1 (Bio-Rad, Hertfordshire, UK) as indicated in Fig. 2. For each cell line, three independent experiments consisting of triplicate gels for each condition were analyzed; in total 36 gels. Only significant changes of at least 1.4 fold $(p<0.01)$ seen in each gel on each occasion were treated as meaningful. The quantitation and statistical analysis of changes to spot intensity is achieved by (i) generation of an optical density reading for each spot detected; (ii) automatic determination of spot density; (iii) generation of Gaussian modeling for precise identification and quantitation of spots; (iv) automatic determination of standard deviation and coefficient of variation and $(v)$ conduction of statistical analysis based on the number of replicate groups and the number of gels per group. Each set of 6 gels was analyzed twice using the software.

\subsection{Identification of proteins using peptide mass fingerprinting}

\subsubsection{Sample preparation}

Spots selected by the previous steps were excised and transferred into a 96-well plate using the ProteomeWorks SpotCutter robot (BioRad, Hertfordshire, UK). The excised pieces of gel were processed 
automatically by a MassPREP workstation (Waters, Hertfordshire, UK) performing the following steps: washing/destaining (1:1 mixture of $50 \%(\mathrm{v} / \mathrm{v})$ acetonitrile and $50 \mathrm{mM}$ ammonium bicarbonate), reduction (DTT $10 \mathrm{mM}$, ammonium bicarbonate $100 \mathrm{mM}$ ), alkylation (iodoacetamide $55 \mathrm{mM}$, ammonium bicarbonate $100 \mathrm{mM}$ ), acetonitrile dehydration, digestion (trypsin $6 \mathrm{ng} / \mu \mathrm{L})$, extraction from the gel $(1 \%(\mathrm{v} / \mathrm{v})$ formic acid, $2 \%(\mathrm{v} / \mathrm{v})$ acetonitrile) and finally spotting of the peptides and matrix ( $\alpha$-cyano-4-hydroxycinnamic acid, $2 \mathrm{mg} / \mathrm{mL}$ in $50 \%(\mathrm{v} / \mathrm{v})$ acetonitrile, $0.1 \%(\mathrm{v} / \mathrm{v})$ trifluoroacetic acid) on the MALDI plate (Waters Ltd., Manchester, UK).

\subsubsection{MALDI-TOF MS analysis}

A M@LDI L/R MALDI-TOF mass spectrometer (Waters Ltd., Manchester, UK), operating in positive ion reflectron mode, was used to obtain the peptide mass spectra. Spectra were processed and calibrated externally with a tryptic digest of alcohol dehydrogenase. Internal calibration was performed using a single trypsin autodigestion peak ( $m / z 2211.105)$ as a Lockmass point. Monoisotopic peak masses presenting $\mathrm{m} / \mathrm{z}$ ratios from 900 to 2800 were submitted to the Mascot search engine (Matrix Science Ltd., London, UK; http://www. matrixscience.com) in order to identify proteins.

\subsubsection{Database search for protein identification}

Searches were generally performed using the Swiss-Prot database, up to one missed cleavage site, mass error of $200 \mathrm{ppm}$ and variable modifications of carbamidomethyl (C) and oxidation (M). Further details of parameters used and any variations are detailed in Supporting Information. Protein identifications were accepted on the following criteria: five or more matching peptides; a MOWSE score of more than 56 ; sequence coverage greater than $20 \%$. Details of peptide mass lists used for searches and proteins identified are supplied in Appendix A.

\subsection{Identification of proteins using MALDI-TOF tandem mass spectrometry}

\subsubsection{Sample preparation}

Spots selected by the previous steps were excised and washed twice with ultra-pure water, modified digestion buffer ( $1: 1$ mixture of $100 \mathrm{mM}$ ammonium bicarbonate and 50\% (v/v) acetonitrile), 100\% acetonitrile and $100 \mathrm{mM}$ ammonium bicarbonate. Subsequently, excised pieces of gel were washed with $100 \%(\mathrm{v} / \mathrm{v})$ acetonitrile, dried for $20 \mathrm{~min}$ at $37^{\circ} \mathrm{C}$ and incubated with $10 \mu \mathrm{L}$ of sequencing grade trypsin $(12.5 \mathrm{ng} / \mu \mathrm{L})$ in digestion buffer, on ice for $15 \mathrm{~min}$. The supernatant was removed and replaced with $50 \mathrm{mM}$ ammonium bicarbonate. The trypsin digestion was carried out for $12-16 \mathrm{~h}$ at $37^{\circ} \mathrm{C}$. The supernatant of the digestion was then transferred into a new tube and the excised pieces of gel were extracted with $50 \%(\mathrm{v} / \mathrm{v})$ acetonitrile, $0.1 \%(\mathrm{v} / \mathrm{v})$ trifluoroacetic acid, and $100 \%(\mathrm{v} / \mathrm{v})$ acetonitrile washes. Subsequently, excised pieces of gel were sonicated and the supernatant was pooled with the supernatant of the digestion. Extracted peptides were vacuum-centrifuged (Vacufuge, Eppendorf France SARL, Le Pecq, France) and resuspended in $10 \mu \mathrm{L} 0.1 \%(\mathrm{v} / \mathrm{v})$ trifluoroacetic acid. Extracted peptides were desalted with $\mathrm{C} 18$ reverse-phase Zip-Tip (Millipore, Molsheim, France) according to the manufacturer's instructions. Peptides were eluted with $2.5 \mu \mathrm{L}$ of $50 \%(\mathrm{v} / \mathrm{v})$ acetonitrile, $0.1 \%(\mathrm{v} / \mathrm{v})$ trifluoroacetic acid, and mixed at a 1:1 ratio with MALDI matrix $(10 \mathrm{mg} / \mathrm{mL} \alpha$-cyano-4-hydroxy-cinnamic acid (CHCA) matrix in $70 \%(\mathrm{v} / \mathrm{v})$ acetonitrile, $0.1 \%(\mathrm{v} / \mathrm{v})$ trifluoroacetic acid) for spotting.

\subsubsection{MALDI-TOF MS/MS analysis}

MS and MS/MS analyses of tryptic peptides were performed using the 4800 MALDI-TOF/TOF Analyzer (Applied Biosystems/MDS Sciex, California, USA). After screening all MALDI sample positions in MSpositive reflector mode using 2000 laser shots between $\mathrm{m} / \mathrm{z} 750$ and 4000 , the fragmentation of automatically selected precursors was performed at a collision energy of $1 \mathrm{kV}$ using air as collision gas (pressure, $\sim 2 \times 10^{-6}$ Torr). Up to 15 of the most intense ion signals per spot position having an $\mathrm{S} / \mathrm{N}$ greater than 80 were selected as precursors for MS/MS acquisition.

\subsubsection{Database search for protein identification}

Protein identification was performed by peptide mass fingerprinting and/or specific MS/MS peptide sequencing. The combined MS and MS/MS spectra from were processed using ProteinPilot 3.0 software program (Applied Biosystems, California, USA) with Mascot (Matrix Science Ltd., London, UK; http://www.matrixscience.com) as the database search engine (V 2.0). Searches were performed against the IPI human database, version 3.66. The Mascot searches were run using the following parameters: methionine oxidation $(\mathrm{M})$ as variable, cysteine carbamidomethylation (C) as fixed; one missed cleavage allowed; precursor tolerance at $50 \mathrm{ppm}$, MS/MS fragment tolerance set to $0.2 \mathrm{Da}$, and charge set to +1 . Identification was assigned to a protein spot feature if the protein score was calculated to be greater than 60 , correlating to a confidence interval greater than $95 \%$ (Table 1).

\subsection{Flow cytometry confirmation of eEF2 and GRB2}

Cells were fixed in $1 \%(\mathrm{v} / \mathrm{v})$ paraformaldehyde and subsequently resuspended in PBS. Cell concentration was adjusted to $2 \times 10^{6}$ cells/ $\mathrm{mL}$ and an aliquot of $500 \mu \mathrm{L}$ was permeabilized in $2 \times$ permeabilization buffer (PBS, $2.5 \mathrm{mM}$ EDTA, 4\% (v/v) fish skin gelatin and 1\% $(\mathrm{v} / \mathrm{v})$ Triton X-100). Permeabilized cells were incubated with rabbit antihuman eEF2 (phosphor T56 + T58) (Abcam, UK) and GRB2 (Y209) (Abnova, Taiwan) as primary antibody and subsequently incubated with a goat anti-rabbit IgG-PE-conjugated secondary antibody. Flow cytometry quantitative analysis was conducted using a FACSCalibur (Becton Dickinson, UK). Analysis of data was performed using the CellQuest ${ }^{\mathrm{TM}}$ Software (Becton Dickinson, UK). Results are presented in Arbitrary Units (AU) resulting from the ratio between the mean fluorescence intensity (MFI) of unstained samples (negative control samples) and stained samples (vehicle control and treated samples). Each experiment contained a negative control consisting of untreated Jurkat E6.1 or RPMI1788 cells. While vehicle control and treated samples were incubated with respective antibodies, negative control samples were not stained with any antibodies. At the end of the experimental procedure, negative control samples were analyzed in the same manner as vehicle control and treated samples. Reproducibility was assured by conducting three independent experiments with each sample repeated at least three times.

\subsection{Statistical analysis}

Cell viability results are presented as means $\pm S D$. Overall experimental reproducibility was assured by conducting five independent experiments consisting of triplicate repeats of vehicle control samples and treated samples. Overall experimental reproducibility of 2-DE gel results was assured by conducting three independent experiments comprising triplicate repeats of vehicle control gels and treated gels. In total, 18 gels were run for each cell line. Statistical differences were evaluated with a Student's t-test, $p<0.01$ using the statistical package included in PDQuest software version 7.3.1 (BioRad, Hertfordshire, UK). Flow cytometry experiments are presented as mean of $A U \pm S D$. Overall experimental reproducibility was assured by conducting three independent experiments consisting of three repeats of vehicle control samples and treated samples. For cell viability and flow cytometry experimental approaches, differences were evaluated with a Student's $t$-test, $p<0.01$ (SPSS 15.0, USA). 
Table 1

Proteins exhibiting change in phosphorylation state in Jurkat E6.1 lymphocyte cell line (spots 1-4) and RPMI1788 lymphocyte cell line (spots 5-6), identified by MALDI-TOF MS and MALDI-TOF MS/MS. Statistical significance was considered at $p \leq 0.01$ ( $t$-test).

\begin{tabular}{|c|c|c|c|c|c|c|c|c|c|c|c|c|c|}
\hline \multirow[b]{2}{*}{ Spot } & \multirow[b]{2}{*}{ Protein Identified } & \multirow[b]{2}{*}{$\begin{array}{l}\text { Identified } \\
\text { in }\end{array}$} & \multirow[b]{2}{*}{$\begin{array}{l}\text { Accession } \\
\text { number } \\
\text { (UniProtKB) }\end{array}$} & \multicolumn{3}{|c|}{ MALDI-TOF MS } & \multicolumn{7}{|c|}{ MALDI-TOF MS/MS } \\
\hline & & & & $\begin{array}{l}\text { MOWSE } \\
\text { score }\end{array}$ & $\begin{array}{l}\text { Peptides } \\
\text { matched }\end{array}$ & $\begin{array}{l}\text { Sequence } \\
\text { coverage } \\
(\%)\end{array}$ & $\begin{array}{l}\text { MOWSE } \\
\text { score }\end{array}$ & $\begin{array}{l}\text { Peptides } \\
\text { matched }\end{array}$ & $\begin{array}{l}\text { Sequence } \\
\text { coverage } \\
(\%)\end{array}$ & $\begin{array}{l}\mathrm{Mw} \\
(\mathrm{kDa})\end{array}$ & $\mathrm{pI}$ & $\begin{array}{l}\text { Phosphorylation } \\
\text { State }\end{array}$ & $\begin{array}{l}\text { Fold } \\
\text { change }\end{array}$ \\
\hline 1 & $\begin{array}{l}\text { Nucleoside diphosphate } \\
\text { kinase A }\end{array}$ & $\begin{array}{l}\text { Jurkat } \\
\text { E6.1 }\end{array}$ & P15531 & 82 & 7 & $53 \%$ & 147 & 9 & $42 \%$ & 17.3 & 5.83 & Up & 1.9 \\
\hline 2 & $\begin{array}{l}\text { C-1-tetrahydrofolate synthase, } \\
\text { cytoplasmic }\end{array}$ & $\begin{array}{l}\text { Jurkat } \\
\text { E6.1 }\end{array}$ & P11586 & 164 & 25 & $31 \%$ & 51 & 17 & $15 \%$ & 102 & 6.89 & Up & 2.5 \\
\hline 3 & $\begin{array}{l}\text { Heat shock cognate } 71 \mathrm{kDa} \\
\text { protein }\end{array}$ & $\begin{array}{l}\text { Jurkat } \\
\text { E6.1 }\end{array}$ & P11142 & 126 & 14 & $26 \%$ & 155 & 14 & $27 \%$ & 71.1 & 5.37 & Down & 5.9 \\
\hline 4 & Eukaryotic elongation factor 2 & $\begin{array}{l}\text { Jurkat } \\
\text { E6.1 }\end{array}$ & P13639 & 160 & 31 & $36 \%$ & 317 & 22 & $28 \%$ & 96.2 & 6.41 & Up & 1.9 \\
\hline 5 & $\begin{array}{l}\text { Eukaryotic translation initiation } \\
\text { factor } 3 \text { subunit I }\end{array}$ & $\begin{array}{l}\text { RPMI } \\
1788\end{array}$ & Q13347 & 151 & 14 & $58 \%$ & 332 & 11 & $37 \%$ & 36.9 & 5.38 & Up & 1.4 \\
\hline 6 & $\begin{array}{l}\text { Growth factor receptor-bound } \\
\text { protein } 2\end{array}$ & $\begin{array}{l}\text { RPMI } \\
1788\end{array}$ & P62993 & 84 & 10 & $41 \%$ & 91 & 3 & $10 \%$ & 25.3 & 5.89 & Down & 4.7 \\
\hline
\end{tabular}

\section{Results}

\subsection{Measurement of cell viability}

As can be seen in Fig. 1, the two cell lines differ in their sensitivity to DON with a higher dose required in RPMI1788 cells to induce a similar reduction in cell viability. In both cell lines reduced cell viability is generally seen after $24 \mathrm{~h}$ incubation. When compared to

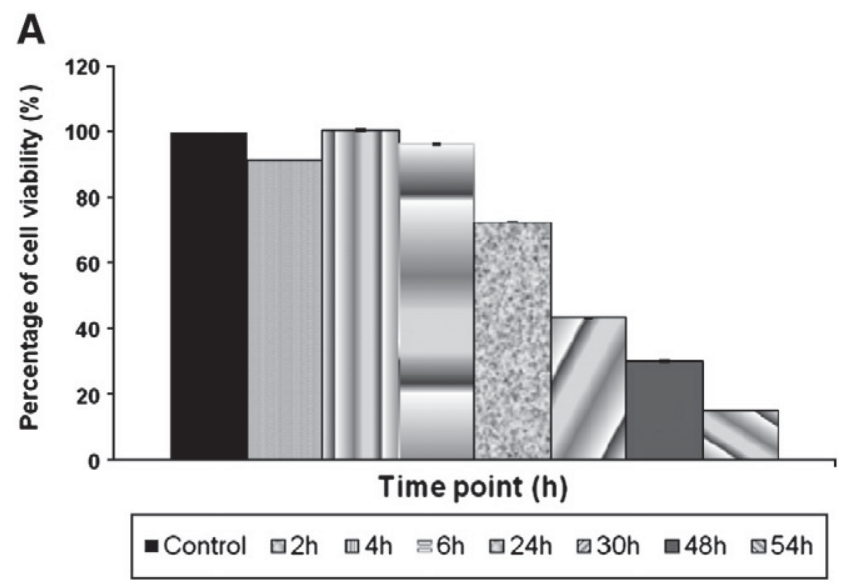

\section{B}

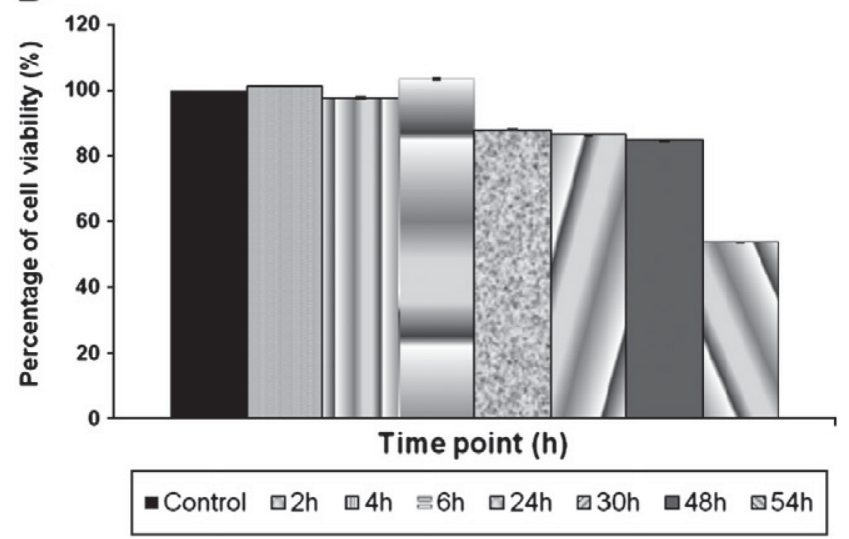

Fig. 1. Cell viability of DON in (A) Jurkat E6.1 cells at $250 \mathrm{ng} / \mathrm{mL}$ and (B) RPMI1788 cells at $500 \mathrm{ng} / \mathrm{mL}$ measured by the MTT assay. Each bar represents the mean $\pm \mathrm{SD}$ of fifteen replicates. SD values below $3 \%$. vehicle-control cells, the concentrations of 250 and $500 \mathrm{ng}$ DON/ml gave a statistically significant reduction in the cell viability in Jurkat E6.1 and RPMI1788, respectively $(p<0.01)$. For proteomics studies, each cell line was treated for $24 \mathrm{~h}$ at its respective concentration.

\subsection{Two-dimensional gel electrophoresis and protein identification}

Using 2D-gel electrophoresis as described in the Methods, an average of over 1000 spots was detected per gel and analyzed using PDQuest software. Four spots showed reproducible phosphorylation changes in Jurkat E6.1 cells and two spots in RPMI1788 cells (Fig. 2, Appendix B); all spots showed at least a 1.4 fold (Appendix B). Findings were reproducible across all gels within each experiment and in three separate experimental treatments $(p<0.01)$.

All spots from Jurkat E6.1 and RPMI1788 cells were successfully identified using both MALDI-TOF MS and MALDI-TOF MS/MS (Appendix A). In Jurkat E6.1 cells, C1-THF synthase, eEF2 and NDKA all exhibited up-regulation in DON treated samples, while Hsc70 exhibited down-regulation in DON treated samples. In RPMI 1788 cells, eIF3i was found to be up-regulated by DON treatment, while GRB2 was found to be down-regulated by DON treatment. No significant changes to quantitative expression of these proteins were identified. The proteins identified are involved in metabolism regulation, protein biosynthesis, co-chaperoning and signaling transduction (Table 2).

\subsection{Flow cytometry confirmation of eEF2 and GRB2}

Antibodies were only available for two of the above proteins, eEF2 and GRB2, and thus permitted the use of flow cytometry to confirm changes in protein phosphorylation state. Comparison between control and treated samples showed an up-regulation of 1.3-fold in eEF2 in Jurkat E6.1 cells and a 2.5-fold down-regulation in GRB2 in RPMI1788 cells (Fig. 3, Appendix B). All experiments contained a negative control to account for auto-fluorescence. The results are statistically significant $(p<0.01)$ and confirm the pattern of expression which was obtained using $2-\mathrm{DE}$.

\section{Discussion}

Current studies investigating biomarkers for DON exposure have recently resulted in the identification of DON and its glucuronide in urine as a useful biomarker of exposure in population-based studies $[13,14,19]$. We have previously identified nine potential mechanismbased biomarkers for DON exposure, however, no phosphoprotein 

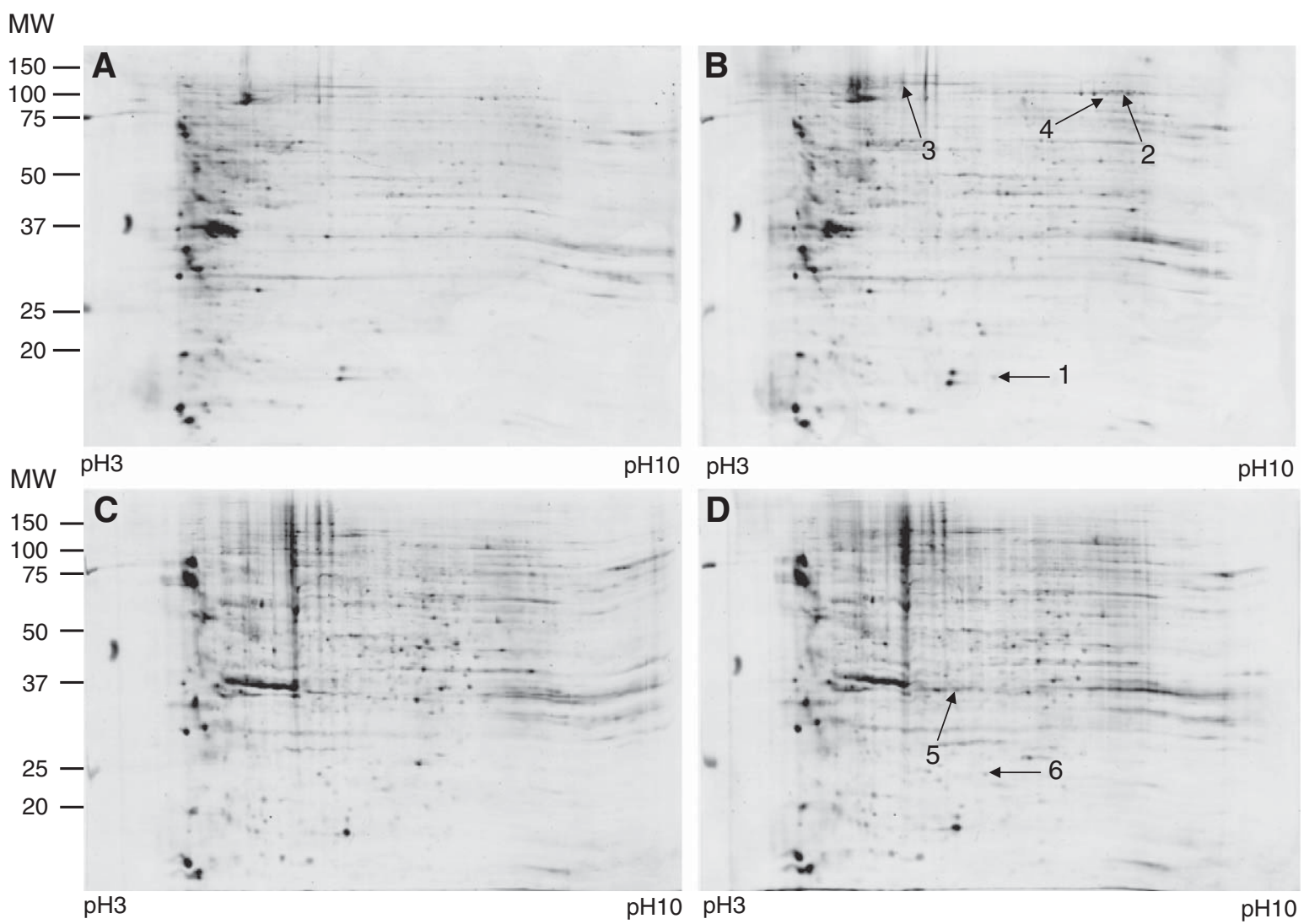

Fig. 2. Image of representative 2-DE gels of (A) Jurkat E6.1 control cells, (B) Jurkat E6.1 treated cells at $250 \mathrm{ng}$ DON/mL, (C) RPMI1788 control cells and (D) RPMI1788 treated cells at $500 \mathrm{ng}$ DON/mL. All gels were stained with Pro-Q Diamond phosphoprotein gel stain. Molecular range from $250 \mathrm{kDa}-10 \mathrm{kDa}$, pI range from 3-10. Highlighted are six spots showing change in phosphorylation state following DON exposure.

biomarkers have been identified to date utilizing a proteomics approach. Here we identify candidate mechanism-based phosphoproteins associated with low dose exposure to DON using Jurkat E6.1 and RPMI1788 cells as models. The use of immortalized cell lines has several advantages such as the cells being easy to grow and maintain, provide unlimited experimental material, among others. Although it has been documented that Jurkat E6.1 cells have specific abnormalities [18], they have been widely and successfully used in signaling transduction investigation [20] to reveal real, normal events which were further validated in other models [18,21]. RPMI1788 cells have also been used in several signaling transduction studies [22], although due to their primary origin these cells do not raise the same objections as Jurkat E6.1 cells. Nevertheless, validation of results in immortalized cells should be sought with primary cells prior to application in populationbased studies. Therefore while recognizing the need for caution in interpretation of results from immortalized cells, we consider that, based on the use of both cell lines in previously relevant work, the results presented are both valid and valuable.

Table 2

Groupings of proteins based on putative function.

\begin{tabular}{ll}
\hline Putative function & Proteins identified \\
\hline Nucleotide metabolism & Nucleoside diphosphate kinase A \\
$\begin{array}{l}\text { Folate-mediated one-carbon } \\
\text { metabolism }\end{array}$ & C-1-tetrahydrofolate Synthase \\
Co-chaperoning & Heat shock cognate 71 kDa protein \\
Protein biosynthesis & Eukaryotic translation initiation factor 3 subunit I \\
& Eukaryotic elongation factor 2 \\
Signaling transduction & Growth factor receptor-bound protein 2 \\
\hline
\end{tabular}

We had previously determined that a concentration of $250 \mathrm{ng}$ and $500 \mathrm{ng}$ DON/mL for Jurkat E6.1 and RPMI1788 cells respectively induced changes to the proteome while limiting the levels of reduced cell viability due to DON exposure. Reduced cell viability due to DON exposure in the current series of experiments was similar to previous data and thus we selected doses and an exposure period (24 h) associated with modest $(\sim 20 \%)$ reduction in cell viability in the two cell lines representing doses at the lower end of a range used by others $[23,24]$. The above mentioned exposure period was also chosen based on previous studies analyzing the effects of DON on immune cell lines [16], on reproducibility and reduced variability of cell viability and a significant decrease in cell viability after a $30 \mathrm{~h}$ exposure period. As our objective was to induce low to moderate changes to cell viability, a $24 \mathrm{~h}$ exposure period was shown to be a reasonable compromise between establishing a real effect consistent with human exposure and the induction of cell death.

Four proteins from Jurkat E6.1 cells and two proteins from RPMI 1788 cells displayed altered phosphorylation states reproducibly across gel sets (Fig. 2) and their functional roles are discussed below.

\subsection{Nucleotide metabolism}

The phosphorylation of nucleoside diphosphate kinase A (NDKA; E.C. 2.7.4.6) was up-regulated in Jurkat E6.1 cells after DON exposure. This protein has been shown to be involved in DNA regulation, signal transduction and the synthesis of nucleoside triphosphates in both purine and pyrimidine pathways $[25,26]$. Studies on the phosphorylation of NDKA have identified this protein as a potential biomarker for several types of cancer [27-29]. In Jurkat E6.1 and peripheral blood mononuclear cells, NDKA phosphorylation has been associated with T 
A

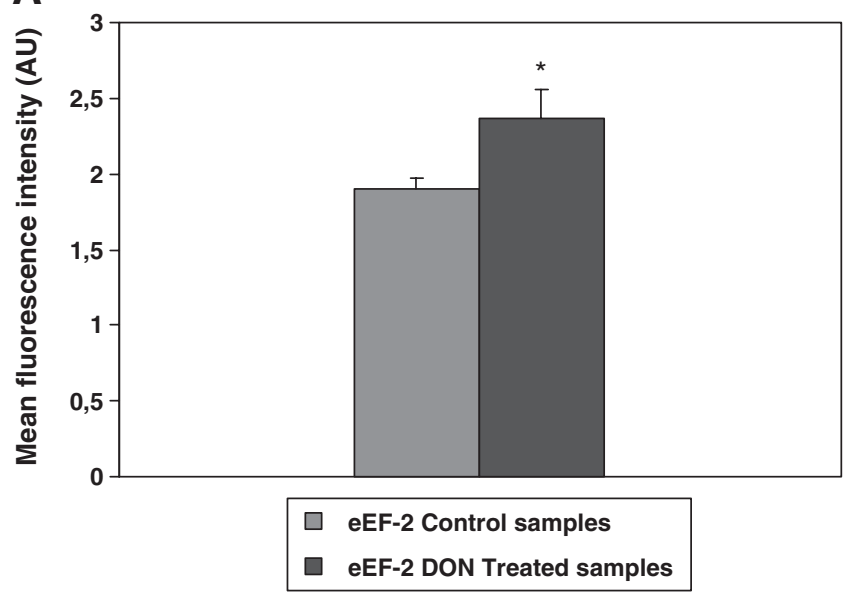

B

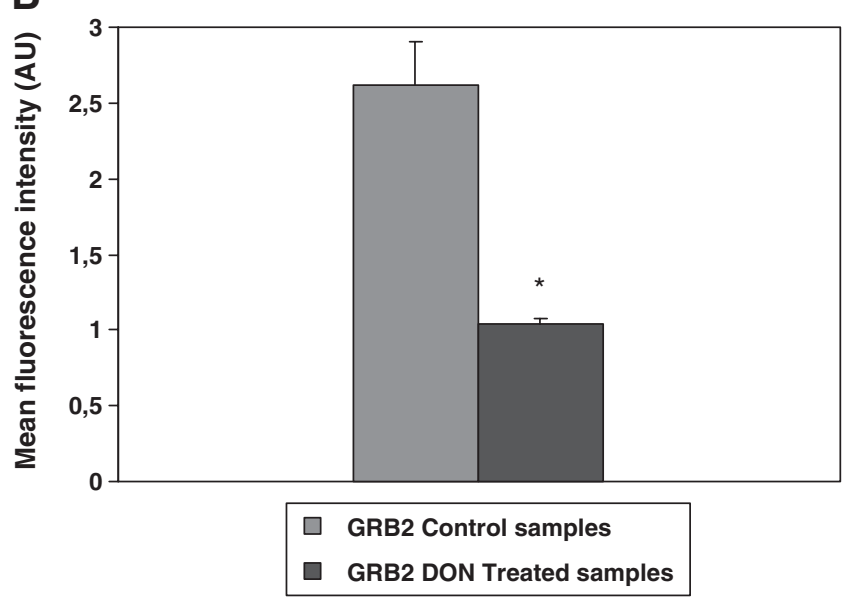

Fig. 3. Quantitative confirmation of changes to phosphorylation state in (A) eEF2 and (B) GRB2 measured by flow cytometry. Each bar represents the mean arbitrary units \pm SD of three independent experiments each consisting of three replicates after negative control normalization. $\left({ }^{*} p<0.01\right)$.

cell receptor signaling, protein-protein interaction [30], cell survival and subsequent activation of cytokine production [31].

Thus, the phosphorylation of NDKA may interfere with GTP production, thereby affecting the likes of DNA and RNA synthesis, glycine and riboflavin metabolism and folate biosynthesis, all of which depend on GTP levels. However, to date, no studies have associated the phosphorylation of NDKA with DON exposure. This observation reinforces our findings which suggest that an up-regulation in quantitative expression of Inosine-5'-monophosphate dehydrogenase 2 (IMDH2) and GMP synthase (GMPS) in Jurkat E6.1 cells exposed to DON may influence purine metabolism. Nevertheless, the association of this metabolic pathway with immune cell function after DON exposure still remains poorly understood.

\subsection{Folate-mediated one carbon metabolism}

The phosphorylation state of C-1-tetrahydrofolate synthase (C1-THF synthase) was found to be up-regulated in Jurkat E6.1 cells. C1-THF synthase is involved in DNA synthesis as it provides 10-formyl-THF and 5,10-Methylene-THF for the de novo synthesis of nucleotides and is considered a structural component in a multi-enzymatic purine synthesizing complex [32]. Studies have associated C1-THF synthase as critical to foetal development and intrauterine growth restriction. Recently, proteomic approaches have identified this protein as a potential marker for different types of cancer $[33,34]$.
This effect of DON is intriguing given the observations on the upregulation of NDKA phosphorylation as well as the reported changes in quantitative expression of IMDH2 and GMPS in Jurkat E6.1 cells exposed to DON. Therefore, it would be highly informative to investigate more deeply the relation between C1-THF synthase phosphorylation, DON exposure and nucleotide metabolism.

\subsection{Co-chaperoning}

The phosphorylation of heat shock cognate $71 \mathrm{kDa}$ protein (Hsc70) was down-regulated in Jurkat E6.1 cells after DON exposure. Hsc70 is known to have several cellular functions such as regulating the import of proteins into the nucleus, functioning as an ATPase in the disassembly of vesicles during trafficking and facilitating correct protein folding by binding to nascent polypeptides [35,36]. Studies conducted in lymphocytes isolated from human peripheral blood mononuclear cells reported that Hsc70 expression regulates the development of B lymphocytes and is a potential target of tyrosine kinase activity in $\mathrm{T}$ lymphocytes. It has been associated with increases in inflammation and susceptibility to autoimmunity as well as regulating the myocardial immune response [37-40].

\subsection{Protein biosynthesis}

The phosphorylation of eukaryotic translation initiation factor 3 subunit I (eIF3i) and eEF2 were found to be up-regulated in RPMI1788 and Jurkat E6.1 cells, respectively. These proteins are directly involved in protein biosynthesis. The initiation phase of translation involves the activation of several proteins such as eIF3. This protein and its different subunits have several functions such as binding to the $40 \mathrm{~S}$ subunit of the ribosome and recruiting mRNA [41-43]. Although eIF3 plays important roles at multiple stages in the initiation of translation, the molecular basis for many of its activities are poorly understood. eIF3i has been suggested as a candidate tumour marker in hepatocellular carcinoma and in human amniotic epithelial cells after exposure to the carcinogen anti-benzo[a]pyrene-7,8-dihydrodiol-9,10-epoxide $[44,45]$. The up-regulation of eIF3i here presented reinforces a study on ribotoxic stress response induced by DON, where it was reported that Protein Kinase R (PKR) was rapidly activated and this was characterized by phosphorylation of an eukaryotic initiation factor, eIF2 $\alpha$ [46]. It is also known that eIF3i is phosphorylated by the TGF- $\beta$ type II receptor, allowing this protein to recruit signaling components to receptor tyrosine kinases, and studies have shown that DON exposure induces changes in mRNA expression of TGF- $\beta[47,48]$. One would speculate that if DON exposure affects the TGF- $\beta$ type II receptor, the latter may phosphorylate eIF3i and lead to the impairment of signal transduction and protein synthesis. Recently, changes to quantitative expression of eukaryotic translation factor 3 subunit 1 were identified in EL- 4 cells exposed to DON, further supporting the findings presented here [49].

eEF2 is a member of the GTP-binding translation elongation factor family. It can be phosphorylated at threonine 56 or threonine58 by eEF2 kinase leading to a decrease in eEF2 activity and therefore a decrease in protein biosynthesis by inhibition of mRNA translation elongation [5052]. Studies analyzing the global phosphoproteome of colon and hepatocellular cancer cell lines show that eEF2 phosphorylation is a potential biomarker to assess kinase and signaling pathway activity $[53,54]$.

In summary, the increase in phosphorylation level of eIF3i may lead to the impairment of the correct assembly of active ribosomes, while the increase in phosphorylation of eEF2 may lead to a decrease in protein biosynthesis by inhibition of mRNA translation elongation. The findings support those of other studies looking at protein biosynthesis in lymphoid and other tissues [55]. 


\subsection{Signaling transduction}

GRB2 phosphorylation was down-regulated in RPMI1788 cells after DON exposure. This protein is a regulatory subunit of signaling molecules and pathways whose activity is modulated by tyrosine receptor kinases, providing a link between cell surface growth factor receptors and the Ras signaling pathway [56,57]. Tyrosine phosphorylation of GRB2 interferes with the binding function of SH3 domains to SOS proteins, thereby negatively influencing transcription factor activation and proinflammatory responses. Studies in mouse $T$ lymphocytes identified GRB2 as a potential target for caspase activity when ROS are present. Studies in mouse B lymphocytes have associated GRB2 with B cell antigen receptor activity by sustaining protein kinase activation and prolonged generation of second messengers in myeloid cells [58-60].

In various models, DON has induced phosphorylation of ERK1/2 and transcription factors, such as CREB. Ultimately, these alterations to signaling molecules and transcription factors lead to changes in cytokine expression [61-63]. The down-regulation in GRB2 phosphorylation reported here reinforces the findings reported above.

\subsection{Validation}

To confirm the changes of protein phosphorylation detected using 2-DE, we applied a flow cytometry approach to quantify alterations in eEF2 and GRB2 phosphorylation. The selection of these proteins for validation was based on their biological importance and on the limited availability of commercial antibodies for phosphoproteins. Only two phospho-specific antibodies are currently commercially available, therefore limiting the validation to the proteins mentioned above. Using this approach, it was possible to confirm that both proteins exhibited a similar DON-dependent change of phosphorylation state as seen from the 2-DE approach, as the antibodies chosen where specific for analyzing changes to the phosphorylated state of the proteins.

\section{Conclusions}

This is the first reported study on the effects of DON on the phosphoproteome using a two-dimensional gel electrophoresis approach. We have demonstrated that DON exposure affects metabolic processes such as folate-mediated one carbon and nucleotide metabolism, co-chaperoning, protein biosynthesis and signaling transduction. T and B lymphocytes are different components of the adaptive immune system and it was of interest that we did not detect changes in both. Although B and T lymphocytes have similar developmental origins and share some broad similarities in terms of some of their signaling pathways they are two distinct cell types with different functions. Moreover, it is possible that DON has different targets in the two cell types thus potentially triggering different responses leading to varying proteome changes.

The changes in phosphorylation state reported here are likely to be meaningful taking into account the functional significance of the proteins identified. These results could indicate, therefore, the phosphoproteins are involved to a significant extent in purine metabolism and protein biosynthesis. NDKA and C-1 THF synthase may intervene directly in purine metabolism and indirectly in folate biosynthesis, with NDKA directly involved in purine, RNA and DNA synthesis, and C1-THF being considered a structural component of purine metabolism due to its enzymatic activities in one carbon metabolism. Hsc70, GRB2, eIF3i and eEF-2 all intervene directly or indirectly in protein biosynthesis. These results reinforce previous studies on the effects of DON exposure, indicating the productivity of generating a search for a panel of mechanism-based biomarkers for DON exposure.
It will be of interest to investigate to what extent these potential DON phosphoprotein biomarkers identified in vitro may be reflected in vivo and whether these can be applied to population-based studies of the effects of low dose, chronic DON exposure. This will confirm the value of using cell cultures as reliable indicators of in vivo effects.

Supplementary materials related to this article can be found online at doi:10.1016/j.bbapap.2011.04.001.

\section{Conflict of interest statement}

The authors have declared no conflict of interest.

\section{Acknowledgments}

Protein identification by means of tandem MS was conducted at Plate-forme de Protéomique Médicale, Institut Albert Bonniot Centre de Recherche, INSERM/UJF U823, Centre d'Innovation en Biologie - CHU Grenoble, Grenoble - France coordinated by Dr. Sylvie Michelland and Dr. Michel Sève. Work was supported by the EU Integrated Project NewGeneris, 6th Framework Programme, Priority 5: Food Quality and Safety (Contract no. FOOD-CT-2005-016320; NewGeneris is the acronym of the project 'Newborns and Genotoxic exposure risks' http://www.newgeneris.org) and a grant from the NIEHS, USA ES06052 to CPW.

\section{References}

[1] B.A. Rotter, D.B. Prelusky, J.J. Pestka, Toxicology of deoxynivalenol (vomitoxin), J. Toxicol. Environ. Health 48 (1996) 1-34.

[2] F.Q. Li, Y.W. Li, X.Y. Luo, T. Yoshizawa, Fusarium toxins in wheat from an area in Henan Province, PR China, with a previous human red mould intoxication episode, Food Addit. Contam. 19 (2002) 163-167.

[3] C.P. Wild, A.J. Hall, Epidemiology of mycotoxin related diseases, in: H. Miller (Ed.), The Mycota VI. Human and Animal Relationships, Springer-Verlag, Berlin, 1996, pp. 213-225.

[4] D.M. Hughes, M.J. Gahl, C.H. Graham, S.L. Grieb, Overt signs of toxicity to dogs and cats of dietary deoxynivalenol, J. Anim. Sci. 77 (1999) 693-700.

[5] F. Iverson, C. Armstrong, E. Nera, J. Truelove, S. Fernie, P. Scott, R. Stapley, S. Hayward, S. Gunner, Chronic feeding study of deoxynivalenol in B6C3F1 male and female mice, Teratog. Carcinog. Mutagen. 15 (1995) 283-306.

[6] A. Gutzwiller, L. Czegledi, P. Stoll, L. Bruckner, Effects of Fusarium toxins on growth, humoral immune response and internal organs in weaner pigs, and the efficacy of apple pomace as an antidote, J. Anim. Physiol. Anim. Nutr. 91 (2007) 432-438.

[7] J. van de Walle, B. Romier, Y. Larondelle, Y.-J. Schneider, Influence of deoxynivalenol on NF-kappaB activation and IL-8 secretion in human intestinal Caco-2 cells, Toxicol. Lett. 177 (2008) 205-214.

[8] C.J. Amuzie, J. Shinozuka, J.J. Pestka, Induction of suppressors of cytokine signaling by the trichothecene deoxynivalenol in the mouse, Toxicol. Sci. 111 (2009) 277-287.

[9] P. Pinton, F. Accensi, E. Beauchamp, A.M. Cossalter, P. Callu, F. Grosjean, I.P. Oswald, Ingestion of deoxynivalenol (DON) contaminated feed alters the pig vaccinal immune responses, Toxicol. Lett. 177 (2008) 215-222.

[10] X.A. Wu, M. Kohut, J. Cunnick, T. Bailey, S. Hendrich, Deoxynivalenol suppresses circulating and splenic leukocyte subpopulations in BALB/c mice: dose response, time course and sex differences, Food Addit. Contam. A Chem. Anal. Control Expo. Risk Assess. 26 (2009) 1070-1080.

[11] J.J. Pestka, A.T. Smolinski, Deoxynivalenol: toxicology and potential effects on humans, J. Toxicol. Environ. Health B Crit. Rev. 8 (2005) 39-69.

[12] F.A. Meky, P.C. Turner, A.E. Ashcroft, J.D. Miller, Y.L. Oiao, M.J. Roth, C.P. Wild, Development of a urinary biomarker of human exposure to deoxynivalenol, Food Chem. Toxicol. 41 (2003) 265-273.

[13] P.C. Turner, R.P. Hopton, Y. Lecluse, K.L.M. White, J. Fisher, P. Lebailly, Determinants of urinary deoxynivalenol and de-epoxy deoxynivalenol in male farmers from Normandy, France, J. Agric. Food Chem. 58 (2010) 5206-5212.

[14] P.C. Turner, J.A. Rothwell, K.L.M. White, Y. Gong, J.E. Cade, C.P. Wild, Urinary deoxynivalenol is correlated with cereal intake in individuals from the United Kingdom, Environ. Health Perspect. 116 (2008) 21-25.

[15] E.J. Kim, S.H. Jeong, J.H. Cho, H.O. Ku, H.M. Pyo, H.G. Kang, K.H. Choi, Plasma haptoglobin and immunoglobulins as diagnostic indicators of deoxynivalenol intoxication, J. Vet. Sci. 9 (2008) 257-266.

[16] A. Nogueira da Costa, R.S. Mijal, J.N. Keen, J.B.C. Findlay, C.P. Wild, Proteomic analysis of the effects of the immunomodulatory mycotoxin deoxynivalenol, Proteomics (2011) Mar 9. doi:10.1002/pmic.201000580.

[17] L. Severino, R. Russo, D. Luongo, R. De Luna, R. Ciarcia, M. Rossi, Immune effects of four Fusarium-toxins (FB1, ZEA, NIV, DON) on the proliferation of Jurkat cells and porcine lymphocytes: in vitro study, Vet. Res. Commun. 32 (Suppl 1) (2008) S311-S313. 
[18] R.R. Bartelt, N. Cruz-Orcutt, M. Collins, J.C.D. Houtman, Comparison of T cell receptor-induced proximal signaling and downstream functions in immortalized and primary T cells, PLoS One 4 (2009) e5430.

[19] P.C. Turner, V.J. Burley, J.A. Rothwell, K.L.M. White, J.E. Cade, C.P. Wild, Deoxynivalenol: rationale for development and application of a urinary biomarker, Food Addit. Contam. 25 (2008) 864-871.

[20] R.T. Abraham, A. Weiss, Jurkat T cells and development of the T-cell receptor signalling paradigm, Nat. Rev. Immunol. 4 (2004) 301-308

[21] W. Parson, R. Kirchebner, R. Muhlmann, K. Renner, A. Kofler, S. Schmidt, R. Kofler, Cancer cell line identification by short tandem repeat profiling: power and limitations, FASEB J. 19 (2005) 434-436.

[22] K.S.A. Khabar, L. al-Haj, F. al-Zoghaibi, M. Marie, M. Dhalla, S.J. Polyak, B.R.G. Williams, Expressed gene clusters associated with cellular sensitivity and resistance towards anti-viral and anti-proliferative actions of interferon, J. Mol. Biol. 342 (2004) 833-846.

[23] Y. Sugita-Konishi, J.J. Pestka, Differential upregulation of TNF-alpha, IL-6, and IL8 production by deoxynivalenol (vomitoxin) and other 8-ketotrichothecenes in a human macrophage model, J. Toxicol. Environ. Health A 64 (2001) 619-636.

[24] R.L. Uzarski, Z. Islam, J.J. Pestka, Potentiation of trichothecene-induced leukocyte cytotoxicity and apoptosis by TNF-alpha and Fas activation, Chem. Biol. Interact. 146 (2003) 105-119.

[25] M. Murakami, R. Kaul, P. Kumar, E.S. Robertson, Nucleoside diphosphate kinase/ Nm23 and Epstein-Barr virus, Mol. Cell. Biochem. 329 (2009) 131-139.

[26] J. Biggs, E. Hersperger, P.S. Steeg, L.A. Liotta, A. Shearn, A drosophila gene that is homologous to a mammalain gene associated with tumor metastasis codes for a nucleoside diphosphate kinase, Cell 63 (1990) 933-940.

[27] N. Hailat, D.R. Keim, R.F. Melhem, X.X. Zhu, C. Eckerskorn, G.M. Brodeur, C.P. Reynolds, R.C. Seeger, F. Lottspeich, J.R. Strahler, S.M. Hanash, High levels of p19/ nm23 protein in neuroblastoma are associated with advanced stage disease and with N-myc gene amplification, J. Clin. Invest. 88 (1991) 341-345.

[28] J. Okabe-Kado, T. Kasukabe, Y. Honma, H. Kobayashi, N. Maseki, Y. Kaneko, Extracellular NM23 protein promotes the growth and survival of primary cultured human acute myelogenous leukemia cells, Cancer Sci. 100 (2009) 1885-1894.

[29] B. Youn, H.D. Kim, J. Kim, Nm23-H1/nucleoside diphosphate kinase as a key molecule in breast tumor angiogenesis, Expert Opin. Ther. Targets 12 (2008) $1419-1430$.

[30] V. Mayya, D.H. Lundgren, S.I. Hwang, K. Rezaul, L.F. Wu, J.K. Eng, V. Rodionov, D.K. Han, Quantitative phosphoproteomic analysis of T cell receptor signaling reveals system-wide modulation of protein - protein interactions, Sci. Signal. 2 (2009) A37-A52.

[31] J. Okabe-Kado, T. Kasukabe, Y. Honma, H. Kobayashi, N. Maseki, Y. Kaneko, Extracellular NM23-H1 protein inhibits the survival of primary cultured normal human peripheral blood mononuclear cells and activates the cytokine production, Int. J. Hematol. 90 (2009) 143-152.

[32] A.J. MacFarlane, C.A. Perry, H.H. Girnary, D. Gao, R.H. Allen, S.P. Stabler, B. Shane, P. J. Stover, MTDHFD1 is an essential gene in mice and alters biomarkers of impaired one-carbon metabolism, J. Biol. Chem. 284 (2009) 1533-1539.

[33] K.M. Howard, S.J. Muga, L.W. Zhang, A.E. Thigpen, D.R. Appling, Characterization of the rat cytoplasmic C-1-tetrahydrofolate synthase gene and analysis of its expression in liver regeneration and fetal development, Gene 319 (2003) 85-97.

[34] S. Gez, B. Crossett, R.I. Christopherson, Differentially expressed cytosolic proteins in human leukemia and lymphoma cell lines correlate with lineages and functions, Biochim. Biophys. Acta Proteins Proteomics 1774 (2007) 1173-1183.

[35] T. Ivanovic, M.A. Agosto, K. Chandran, M.L. Nibert, A role for molecular chaperone Hsc70 in reovirus outer capsid disassembly, J. Biol. Chem. 282 (2007) 12210-12219.

[36] S.L. Nunes, S.K. Calderwood, Heat shock gactor I and the heat shock cognate 70 protein associate in high molecular weight complexes in the cytoplasm of $\mathrm{NIH}-$ 3T3 cells, Biochem. Biophys. Res. Commun. 213 (1995) 1-6.

[37] M.U. Alam, J.A. Harken, A.M. Knorn, A.R. Elford, K. Wigmore, P.S. Ohashi, D.G. Millar, Transgenic expression of Hsc70 in pancreatic islets enhances autoimmune diabetes in response to beta cell damage, J. Immunol. 183 (2009) 5728-5737.

[38] M. Egerton, R.L. Moritz, R. Druker, A. Kelso, L.J. Simpson, Identification of the 70kD heat shock cognate protein (Hsc70) and alpha-actinin-1 as novel phosphotyrosine-containing proteins in T lymphocytes, Biochem. Biophys. Res. Commun. 224 (1996) 666-674

[39] P.S. Wehner, B. Nielsen, M. Hokland, Expression levels of hsc70 and hsp60 are developmentally regulated during B-cell maturation and not associated to childhood c-ALL at presentation or relapse, Eur. J. Haematol. 71 (2003) 100-108.

[40] N. Zou, L.H. Ao, J.C. Cleveland, X.P. Yang, X. Su, G.Y. Cai, A. Banerjee, D.A. Fullerton, X.Z. Meng, Critical role of extracellular heat shock cognate protein 70 in the myocardial inflammatory response and cardiac dysfunction after global ischemiareperfusion, Am. J. Physiol. Heart Circ. Physiol. 294 (2008) H2805-H2813.

[41] C.M. Fletcher, T.V. Pestova, C.U.T. Hellen, G. Wagner, Structure and interactions of the translation initiation factor eIF1, EMBO J. 18 (1999) 2631-2637.
[42] N. Methot, M.S. Song, N. Sonenberg, A region rich in aspartic acid, arginine, tyrosine, and glycine (DRYG) mediates eukaryotic initiation factor 4B (eIF4B) self-association and interaction with eIF3, Mol. Cell. Biol. 16 (1996 5328-5334.

[43] L. Valasek, K.H. Nielsen, A.G. Hinnebusch, Direct eIF2-eIF3 contact in the multifactor complex is important for translation initiation in vivo, EMBO J. 21 (2002) 5886-5898

[44] X.H. Chen, S.B. Fu, F. Chen, H.Y. Chen, Z. Chen, Identification of tumor-associated antigens in human hepatocellular carcinoma by autoantibodies, Oncol. Rep. 20 (2008) 979-985.

[45] W.Y. Shen, H. Liu, Y.N. Yu, Translation initiation proteins, ubiquitin-proteasome system related proteins, and 14-3-3 proteins as response proteins in FL cells exposed to anti-benzo[a]pyrene-7,8-dihydrodiol-9,10-epoxide, Proteomics 8 (2008) 3450-3468.

[46] H.R. Zhou, A.S. Lau, J.J. Pestka, Role of double-stranded RNA-activated protein kinase R (PKR) in deoxynivalenol-induced ribotoxic stress response, Toxicol. Sci. 74 (2003) 335-344

[47] J.I. Azconaolivera, Y. Ouyang, J. Murtha, F.S. Chu, J.J. Pestka, Induction of cytokine messenger-RNAs in mice after oral -exposure to the trichothecene vomitoxin (deoxynivalenol) - Relationship to toxin distribution and protein-synthesis inhibition, Toxicol. Appl. Pharmacol. 133 (1995) 109-120.

[48] Y.J. Chung, H.R. Zhou, J.J. Pestka, Transcriptional and posttranscriptional roles for p38 mitogen-activated protein kinase in upregulation of TNF-alpha expression by deoxynivalenol (vomitoxin), Toxicol. Appl. Pharmacol. 193 (2003) 188-201.

[49] A.M. Osman, J.L.A. Pennings, M. Blokland, A. Peijnenburg, H. van Loveren, Protein expression profiling of mouse thymoma cells upon exposure to the trichothecene deoxynivalenol (DON): implications for its mechanism of action, J. Immunotoxicol. 7 (2010) 147-156.

[50] L. Miranda, S. Horman, I. De Potter, L. Hue, J. Jensen, M.H. Rider, Effects of contraction and insulin on protein synthesis, AMP-activated protein kinase and phosphorylation state of translation factors in rat skeletal muscle, Pflugers Arch. Eur. J. Physiol. 455 (2008) 1129-1140.

[51] N.T. Redpath, N.T. Price, K.V. Severinov, C.G. Proud, Regulation of elongation factor-2 by multisite phosphorylation, Eur. J. Biochem. 213 (1993) 689-699.

[52] A.G. Ryazanov, E.A. Shestakova, P.G. Natapov, Phosphorylation of elongation factor 2 by EF-2 kinase affects rate of translation, Nature 334 (1988) 170-173.

[53] J.E. Kim, S.R. Tannenbaum, F.M. White, Global phosphoproteome of HT-29 human colon adenocarcinoma cells, J. Proteome Res. 4 (2005) 1339-1346.

[54] L. Orsatti, E. Forte, L. Tomei, M. Caterino, A. Pessi, F. Talamo, 2-D Difference in ge electrophoresis combined with Pro-Q Diamond staining: a successful approach for the identification of kinase/phosphatase targets, Electrophoresis 30 (2009) 2469-2476.

[55] S. Doll, J.A. Schrickx, S. Danicke, J. Fink-Gremmels, Deoxynivalenol-induced cytotoxicity, cytokines and related genes in unstimulated or lipopolysaccharide stimulated primary porcine macrophages, Toxicol. Lett. 184 (2009) 97-106.

[56] S.G. Li, A.D. Couvillon, B.B. Brasher, R.A. Van Etten, Tyrosine phosphorylation of Grb2 by $\mathrm{Bcr} / \mathrm{Abl}$ and epidermal growth factor receptor: a novel regulatory mechanism for tyrosine kinase signaling, EMBO J. 20 (2001) 6793-6804.

[57] E. Haines, P. Minoo, Z. Feng, N. Resalatpanah, X.M. Nie, M. Campiglio, L. Alvarez, E. Cocolakis, M. Ridha, M. Di Fulvio, J. Gomez-Cambronero, J.J. Lebrun, S. Ali, Tyrosine phosphorylation of GRB2: role in prolactin/epidermal growth factor cross talk in mammary epithelial cell growth and differentiation, Mol. Cell. Biol. 29 (2009) 2505-2520.

[58] N. Engels, L.M. Konig, C. Heemann, J. Lutz, T. Tsubata, S. Griep, V. Schrader, J. Wienands, Recruitment of the cytoplasmic adaptor Grb2 to surface IgG and IgE provides antigen receptor-intrinsic costimulation to class-switched B cells, Nat. Immunol. 10 (2009) 1018-1764.

[59] T. Kaji, S. Hachimura, W. Ise, S. Kaminogawa, Proteome analysis reveals caspase activation in hyporesponsive CD4 T lymphocytes induced in vivo by the ora administration of antigen, J. Biol. Chem. 278 (2003) 27836-27843.

[60] Y. Liu, W.G. Zhang, Identification of a new transmembrane adaptor protein that constitutively binds Grb2 in B cells, J. Leukoc. Biol. 84 (2008) 842-851.

[61] Y. Moon, H. Yang, S.H. Lee, Modulation of early growth response gene I and interieukin-8 expression by ribotoxin deoxynivalenol (vomitoxin) via ERK1/2 in human epithelial intestine 407 cells, Biochem. Biophys. Res. Commun. 362 (2007) 256-262.

[62] J.J. Pestka, R.L. Uzarski, Z. Islam, Induction of apoptosis and cytokine production in the Jurkat human $\mathrm{T}$ cells by deoxynivalenol: role of mitogen-activated protein kinases and comparison to other 8-ketotrichothecenes, Toxicology 206 (2005) 207-219.

[63] H.R. Zhou, Z. Islam, J.J. Pestka, Rapid, sequential activation of mitogen-activated protein kinases and transcription factors precedes proinflammatory cytokine mRNA expression in spleens of mice exposed to the trichothecene vomitoxin, Toxicol. Sci. 72 (2003) 130-142. 